\title{
Teachers' Role in the Application of Communicative Language Approach in Teaching Listening and Speaking in Schools in Lugari District, Kenya
}

\author{
Anusu Omondi Maryslessor ${ }^{1 *}$, P. L. Barasa ${ }^{2}$ and Carolyne A. Omulando ${ }^{3}$ \\ ${ }^{1}$ Moi University, School of Education, P. O. Box 3900-30100, Eldoret, Kenya; \\ ${ }^{2}$ Moi University, School of Education, P. O. Box 3900-30100, Eldoret, Kenya; \\ ${ }^{3}$ Moi University, School of Education, P. O. Box 3900-30100, Eldoret, Kenya;
}

\begin{abstract}
The role of the teacher is to be facilitator of his students' learning. Teachers are the managers of classroom activities. They are charged with the responsibility of establishing situations likely to promote communication. This paper is premised on a study which set out to determine if the role of the teacher in a Listening and Speaking class is relevant to the tenets of CLT. A descriptive research design was adopted using direct observation and interview methods for data collection. Note-taking and tape-recording were used to record class proceedings and interviews. A total of twelve secondary schools were selected using stratified and simple random sampling techniques. Fourteen teachers of English were involved. A descriptive analysis of data was done. Frequency tables were used to highlight the data. The findings revealed that while learners were passive participants in the process of learning the listening and speaking skills, the teacher played a very active role. He took centre stage. The teacher concentrated on instructing the learner. He planned the lesson alone, and while in class he talked, asked questions, demonstrated, gave notes, answered questions, explained, narrated, described, responded and even read extracts. The learner was hardly involved. For communicative competence to be achieved, there needs to be less teacher control and more pupil centeredness in any listening and speaking task. The findings of the study may provide impetus for the teacher to reflect upon his own, and other colleagues choice of methodology in the teaching of not only Listening and Speaking but also Reading and Writing. This indeed will boost the performance of English language and make it more acceptable as a language of communication.
\end{abstract}

Keywords: Application, Communicative Language Teaching Approach, Teachers' Role, Teaching Listening, Speaking.

\section{Introduction}

The role of the teacher is to be facilitator of his students' learning [1]. He is the manager of classroom activities. The teacher is charged with the responsibility of establishing situations likely to promote communication. The students are communicators. They learn to communicate by communicating. In CLT, learning activities are selected according to the interests of the learner.

Widdowson [2] observes that the 'natural' way of acquiring a language is slow and inefficient and the purpose of language teaching is to make this process fast and simple. He suggests that language teachers need to assist learners by providing them with frameworks, patterns and rules to develop their communicative language skills. He recommends the use of lexical phrases in language teaching, as they are pragmatic and functional and have a clearly defined role, so they guide students in the flow of conversation and assist them in conveying meaning.

The teacher also has the duty of structuring classrooms in a manner that motivates students. He should focus on both extrinsic and intrinsic motivation. Discussing topics of genuine interest for learners is a useful tool for maintaining and increasing learner motivation. It is important that learners discuss topics of genuine interest to them while learning and practicing in English. The teacher is also charged with the responsibility of creating a conducive classroom environment. Learners' communicative skills can be developed if they are motivated and provided an opportunity to express their identity and relate their feelings to the people around them. They should feel secure and valuable as individuals in their learning atmosphere because a secure learning atmosphere fosters growth of interpersonal relationships between learners themselves and between the learner and the teacher thereby making the class atmosphere safe, encouraging, and accommodating.

Hendrickson [3] believes that CLT should include activities that are interesting to the learners and challenge their linguistic abilities while at the same time, capturing their imagination and motivating them to continue to acquire and use foreign language beyond the textbook and classroom. Language teachers should provide diverse, interesting and abundant communicative activities. Language teachers assist learners in 
developing their communicative ability and help them to express themselves and understand others in social settings.

It is observed that the communicative approach puts emphasis on listening, which implies an active will to try to understand others. "In summary, the role of the teacher as one of listener rather than speaker comes out in CLT" [4]. The teacher should be a patient listener is the basic requirement [5]. Since the teacher talks less and listens more, he becomes an active facilitator of his students learning [6]. The teacher sets up the exercise, but because the students' performance is the goal, the teacher must step back and observe, sometimes acting as referee or monitor. A classroom during a communicative activity is far from quiet. The students do most of the speaking, and frequently the scene of a classroom during a communicative exercise is active.

Because of the increased responsibility to participate, students may find they gain confidence in using the target language in general. Students are more responsible managers of their own learning [6]. The study sought to establish if indeed in the English language classrooms in Lugari District, the CLT approach was used. CLT enhances listening and speaking through interactive tasks such as role-play, public speaking, dictation, debates, among others. These imply learner-centred lessons where the learners perform most of the tasks leaving the teacher as a facilitator. The study, therefore, sought to confirm if this is what happens in Lugari District.

\subsection{Statement of the Problem}

The nature of the language is strictly functional and its purpose is to promote communication. Communication needs both the material to be communicated and the medium to be used to communicate the material. Although oral skills are vital, most learners exhibit lack of mastery of spoken English. Outside the classroom most students use indigenous languages and Sheng at school. Arguing out the case for the use of indigenous languages, Rono et al. [7] say people prefer these to English as they are faster and easier to communicate in. It has also been found out that people code-switch for ease of expression [8]. This explains the apparent minimal use of English.

Emphasis is laid upon the skills of Listening and Speaking because they form a base to the acquisition of the other two skills of reading and writing. To be able to speak, one has to listen. To read and write, one begins by listening and speaking. The two are necessary life skills. Indeed in this study, teachers have attested to this. The Ministry of Education Secondary English Teacher's Handbook points out that wrong forms of spoken English have, over time, become institutionalized in society. They advised that the teacher should therefore endeavour to provide the learner with adequate opportunities to listen to good models of spoken language. The learners should also be provided with ample opportunities to speak English.

The teacher needs to ensure that appropriate opportunities are provided for a learner to develop Listening and Speaking skills. They recommend that reciting poems, telling stories, discussing contemporary issues, debating, dramatizing, performing riddles, role playing and speech drills can facilitate the acquisitions of these two skills in meaningful context. The teaching of listening and speaking skills is the most neglected area in the English program for secondary schools. This is partly explained by the manner of testing. It should be noted that before 2006, these areas were not tested in the final examination. From 2006, they have been examined under paper one.

The nature of examination, however, does not encourage aspects of CLT like role play, dialogue, debate, public speaking, dictation, listening comprehension and others. This is because in the KCSE exam the questions on areas such as dialogue and homophones are leading. Stress and intonation also score very few marks. This, therefore, tempts the teacher to ignore this area and yet oral skills are very important in life. There is need to make the teachers realise that the two skills should not just be taught for purposes of passing exams but for achievement of necessary life skills. Indeed one objective of teaching English is to enable the learner to speak accurately, fluently, confidently and appropriately in a variety of contexts.

CLT which advocates for the actual use of language to do things would be the best approach to take in teaching Listening and Speaking [9]. This could be interpreted to mean that a learner-centred approach that allows learners to debate, discuss, and hold impromptu speeches, role play, dramatize, request, question, answer, direct, advice and do many other things in English would be the best. On the other hand, while the learner does all these things, the teacher takes a peripheral role, becoming the facilitator, the coach, the observer or coparticipant. He is not the man or woman at the centre of the action. The teacher of English has responsibility to the pupils beyond the examination. Outside the classroom, in the institutes of high education and, ultimately, in their respective work places the pupils will need to use and understand English. Surely the teacher must try to equip pupils with the necessary skills to participate in effective communication in the English language in real life, too.

At present most of the Listening and Speaking skills that go on in the classroom might be said to be incidental, in that it often consists of the general teacher talk of the classroom and lesson management [10]. A general look at the Kenyan classroom by researchers such as Theuri [11], Juma [12] and Makhulo [13] reveals 
that this statement is true. The Kenyan teacher is the man/woman at the centre of the learning and teaching action. He plans the lesson alone, goes to class and leads the classroom process. Most of the lesson is spent by the teacher talking, asking questions, demonstrating and even giving notes. The learner is passive. He only answers questions when asked to.

The study set out to investigate if CLT is used in the teaching of Listening and Speaking. This served to create awareness of the need to embrace an approach that meets the learner's needs. This indeed is a response to KNEC [14] exam report which noted that aspects of etiquette were lacking in majority of candidates' responses and yet it is key to interpersonal relations. Such aspects can be dealt with through the CLT approach. In the English paper one exam which tests listening and speaking, in 2006, out of a maximum score of 60, the mean score was 30.71 [14]. This indicates that there is need to do more in listening and speaking. It could therefore be concluded that in the process of learning and teaching, students should be put through an approach that encourages adaptability to various situations; the communicative approach will do just that.

Lugari District cannot as yet boast of good performance in general and more so in English. During the 2007 Lugari District Education day, the DEO noted that there had been a drop in the overall performance. English which had a mean score of 5.126 (C-) fell behind many other subjects like Kiswahili 6.003, Biology 5.393, CRE 8.867, History 6.177 and Geography 5.463. English had a mean score of 5.126 (C-) behind other subjects like Kiswahili which had a score of 6.003, Biology 5.393, CRE 8.867, History 6.177 and Geography which had a score of 5.463. In terms of student individual grades in English, no candidate in the whole district scored an ' $\mathrm{A}$ '. These results indicated that there was a problem in English. The general poor performance in the subject is a pointer that a problem exists. One of the problems could in Paper 1, which was the focus of the study.

The study, therefore, set out to investigate if the CLT approach, which encourages learner participation was being used in the English language classroom in Lugari District.

\subsection{Limitations of the Study}

The limitations of the study stemmed from various factors. The invasive nature of the observing and recording classroom interaction also did pose a challenge. Most of the teachers were not willing to participate as they were suspicious of the researcher. To them the exercise looked like the routine school inspection which they dread. The heads of schools also posed a different form of challenge. Some of them interfered by trying to influence the researcher on whom to observe in class. These heads felt some of their teachers would give a negative picture of the school. To overcome this challenge, the researcher had to persuade; in fact cajole the participants. The significance of the study was explained to them and with the help of acquaintances, the participants relaxed and accepted to be observed, tape recorded and interviewed. The tension in them was so evident that they were eager to hear what the researcher felt about their lessons. Assurances were made that there was no sinister motive behind the study. They were also assured of confidentiality.

Another challenge was that some teachers shortened their lessons deliberately. A 40 minute lesson in one instance lasted only 23 minutes. The teacher appeared to be in a hurry to end the lesson. This could be interpreted to be discomfort on the part of the teacher. A stranger's presence in the classroom and knowledge that they are being observed might influence them to shift their classroom talk [15]. However, in the familiarization meetings to create rapport, no mention was made of the actual aspect of listening and speaking that the researcher sought to investigate. This was to ensure that teachers did not prepare lessons specifically for research.

\section{Materials And Methods}

The study was carried out in public secondary schools in Lugari District of Kakamega County in Western Kenya. The study adopted the descriptive design. This design has been the most widely used in educational research. It could be argued to be the one of the means through which competencies, opinions, attitudes, suggestions, instructions and others can be obtained.

The data required for the study was obtained from respondents in sampled schools. Forms one, two and three students from twelve (12) schools were targeted. The sample size was purposely reduced because of the observation method used for data collection. The Form Four class was excluded because at that level more concentration is on revision for the KCSE exam. A total of 14 lessons of English taught by the same number of teachers were observed. A total of twelve (12) schools were selected from forty-two (42) secondary schools in the District. These schools were selected from each division.

The schools were selected proportionally from each of the following categories of schools: Mixed, Boys and Girls. Using simple random sampling, twelve secondary schools were then selected for the study. To get the good sample of twelve (12) schools, the research used a two-staged sampling procedure, where schools were stratified into girls, boys and mixed schools. The schools were then further stratified into divisions. 
Fourteen (14) lessons of English in twelve (12) schools in Lugari District were observed and recorded. Fourteen teachers were interviewed using an interview schedule.

The instruments used included observation checklists, tape recording and interview guides. Observation and tape recording went on simultaneously in the listening and speaking classes. This was a qualitative research and the data was analyzed qualitatively. The data collected from observations, and interviews was first systematically recorded. It was then reduced to make it more manageable. This was done by teasing out of patterns, themes and groupings. The data was then analyzed through description. Simple frequency tables were used at the end of each description to highlight what had been described. Data on how many schools used the CLT approach and how many did not was shown in frequencies.

\subsection{Teacher Roles}

\section{Results}

The observation checklist was used to seek information on the teacher roles. There are roles spelt out for a teacher attempting to use the CLT approach in teaching listening and speaking. The major role of the teacher in a CLT classroom is to be a facilitator. In the study, the author sought to find out if in the Lugari classrooms the teachers acted as facilitators. This was on the assumption that the listening and speaking skills were taught using the CLT approach. The study, therefore, sought to establish whether the position of the teacher was at the centre or periphery. It was only in lesson 13 where there was an attempt towards a totally learner-centred activity. The teacher in this class had given group work out of class. The learners then came in to give their reports.

Two groups reported their findings orally. The teacher introduced the lesson and asked the first speaker to take the floor. The learner stood at the front of the class and gave his oral presentation. The learner talked for seven minutes after which he allowed the rest of the class to ask questions. He was asked two questions which he answered. The third question proved challenging to him and so he asked his group members to assist him. The teacher, who had been silent all this time, then stepped in to help prompt group members. None of the group members responded forcing the presenter to redirect the questions to the rest of the class. The teacher reiterated. There was then a response from a member of the class. The lesson went on in this pattern with the teacher only coming on occasionally to re-emphasize, clarify and highlight parts of the lesson.

In this lesson, therefore, the roles of the teacher that made her a facilitator included supervising, prompting, explaining, questioning, listening and correcting. This teacher talked for a relatively shorter time (compared to teachers of other listening and speaking lessons). The Learners on the other hand discussed and led the discussion, described, reported and answered questions. The learners were in control of the lesson. This was a good example of a CLT class (Lesson 13).

However, in 13 out of the 14 lessons, the teachers did control lessons even where there was participation from the learners. The teachers talked for most of the lesson. They explained, prompted, questioned, corrected, dictated, created context for language use, demonstrated, directed, monitored work silently, grouped learners, supervised, gave listening tasks, introduced and provided language items. However they did not give the learner ample time to talk. They did most of the talking as seen (sample lesson 2).

\section{Lesson 2, Form 3, 53 Minutes}

Tr: Good morning class.

Lr: Good morning sir.

Tr: Like I told you, today we have a visitor who has come to see how we learn, please welcome her and fell free with her. Madam have a seat please.

Rsr: Thanks.

Tr: So last time we talked about reading. So it is very important for us to read. We want to have or look at an item called LISTENING ACTIVELY. I want you to write on the blackboard, the word communication. Communication. Somebody to do it please. Someone do it (student writes word on board). I see. So when we listen actively, what are the parameters of listening? I want to ask you, how should I know that you have listened to me? Yes?

Lr: When I have eye contact with you.

Tr: Eye contact yes. Anything else?

Lr: When I can understand orders.

Tr: I am not listening. I am not getting you. I am receiving? I am receiving orders? Yeah.

Lr: When you tell me to do something and I do it.

Tr: It is okay, anything else?

Lr: When I nod my head.

Tr: Yeah. So it is important when we listen. Be attentive. Be attentive. I am sure some of you are sleeping, aren't you sleeping? 
Lrs: No.

Tr: Are you day dreaming? You are not day dreaming?

Lr: No.

Tr: So don't day dream when you are listening. Like for example you have objects, what objects can distract you from listening? That, that er, dictionary you have been reading something that you are distracted? Is that not so? It can distract you from listening? So those are some of the items that will distract us from listening. Like you have a newspaper, you are reading English and you doing something else, is it not so?

Lrs: Yes

Tr: Noise (writes on B/B) and the speaker's way of dressing. We want to find out. Come forward (signals to two students). Can you stand up? Stand up. Come forward please. These are the speakers and we are listening to them. Let them say something please (laughter). Let them say anything they have to say. Very fast we don't have time.

Lr 1: Good morning.

Lrs: Good morning.

Lr1: This morning we are going to present about some of the things we need to in order to listen properly. That we must be attentive and we should avoid things e.g for example ...

Tr: What is e.g.? (laughter from class)

Lr 1: For example

Tr: So there is a personal appeal in the things we look at. We are listening to her and we are looking at her hair.

Lr 2: Good morning class.

Lrs: Good morning madam.

Lrs: Today we are here to present our complaints about our food. You all know that the cooks don't give us the share we are supposed to get. (laughter)

Tr: So I want to believe that some of the things we demand, must be things we believe in yourself and that we pray that we shall get them, and? I want people to read this er passage. One paragraph each. I think we shall move there go there and then here. One paragraph each.

Lr 1: I have a dream

Tr: Please, please. Just a minute, can we be able to assist madam with a book. Ok.

Lr 1: I have a dream (noises)

Tr: Those are those distractions. Can we be silent please.

******* READING PASSAGE**************

Tr: Ok, we have heard from this item. We know that some of us have different types of languages. I know that some of us in this class when we say that word Pennsylvania, how do you pronounce it?

Lrs: /penisilivania//penisilivania/

Tr: There are words like now, horror and threshold. How do we pronounce them? How do you pronounce this one?

Lr: /nau/

Tr: And this one? Pronounce it please

Lr: /hcra/

Tr: Louder

Lr: /hcra/

Tr: Louder please please, and this one please.

Lr: /thijold/

Tr: Louder please. Louder, so that people can hear you. So that they can hear you voice. In listening and speaking we should deliberately speak loudly so that people can hear you. You must make effort to listen, er ... no distraction. Nobody should intrude into it. If you go there you must pay attention. You must be interested. Nobody should make you not to listen. Like if Mwai Kibaki has told you today that I am bringing you some loaves. Jirongo has said that I am bringing you a goat. Why should we not listen? Won't you listen to that?

Lrs: Yes

Tr: Berryl what will you not listen to?

Lr: If people didn't want to ...

Tr: No I want you to talk about the items that I have mentioned.

Lr: If he says he is coming to put up a classroom.

Tr: So you don't listen to that?

Lr: Yes.

Tr: What will you listen to? 
Lr: When Kibaki says .... . When Jirongo tells me that this school is going to be closed. That is what I want to find out

Tr: You are looking at your vocals and gestures. How do I know that you have heard something? Ada you have not talked since January

Lr: By maintaining eye contact.

Tr: I am not listening.

Lr: Maintaining

Tr: (gets angry) You see when you are doing that. I have always told you not to put your pen in your mouth. Remove that! (pause). So number two, the way the speaker has put on may distract you. How will it distract you? If it is a man or a woman, how will it distract you?

Lrs: Yes

Tr: Yes if she has put on a mini skirt or whatever you are calling it, will you listen?

Lrs: No

Tr: Why?

Lr: Because she is showing us her thighs .(laughter)

Tr: Your attention will be there? (laughs). So your attention will be taken to that place? That is ok. What do you think of a man? What do you think? For a man what do you ...

Lr: If she ...

Tr: This is a gender sensitive school, why don't we talk of he? She, she, she! We have also men? Please we have two genders. We have men and women. Why don't you talk of men also? Like a duck that follows a route. When one goes there, another one follows. Why don't we use both genders?

Lr: When he comes and he has left his zip open. (laughter)

Tr: ok. Making eye ..........what?

Lr: Contact

Tr: Making constant eye contact. I think we have gone through that novel - The River Between - in literature, is that not so?

Lrs: Yes

Tr: When Waiyaki looks at people what happens?

Lr: They look away.

Tr: Who shies away? Men or women?

Lrs: Both.

Tr: So even men look away?

Lr: Yes

Tr: So we must keep listening. We see she is not listening. We are not in a drama class please. We are in a listening and speaking class so let us not dramatize. We must not be able to dramatize. So what I am saying is you must be able to put your eyes on the speaker always. The eye should not be like when I look that way it must be able to show that way it be able to show that this is what I am reading. If I know that you are not reading..... if I want to know, I just look at you like....... Like when I look at you I want to know. Like I always tell you, you see you are eating your pen and I always tell you not to, don't I? How do I know? Because of the contact eye contact. Another thing is facial expressions. Like if I come here and I just start. I have not said anything, not even good morning. Facial expression means a lot in listening and speaking because you can find out what do I want to say? So you must have some respect for attention. So you must attend to the lesson through and through. Another thing is showing interest in the speech like for example, can I tell you a story? Can I tell you a story?

Lrs: Yes

Tr: Obama won a Nobel prize

Lr: When?

Tr: The Nobel prize went to Obama.

Lr: Why?

Tr: Why? You see now you are wondering why he got it? You see. So you don't know the meaning of the Nobel prize. Who has heard of the Nobel prize?

Lrs: Obama

Tr: Did you know when he got it?

Lrs: Yes

Tr: What did you say when he got it? When Obama gets America gets?

Lrs: Yes 
Tr: But he is a Kenyan boy. Another thing is leaning forward in eagerness for more. How, how are we going to be eager for more? You are listening and I am speaking, how are you going to get more from me?

Lr: When we ask questions?

Tr: So you are eager to know how he got it? So he does not want people to suffer in a conflict. He does not want. He has made sure that people will work together as a unit. That America and the whole world stay in peace. That America as a whole country and the whole world want that. Making inferences. This is the problem. I want us to refer to that book because this is an integrated course. Look at Ngugi Wa Thiong'o's book. Who has a copy? Some of our parents have taken us to some places. Some of us when we have gone to a 'Barasa'. We come back from that place without Lrs: Yes getting what was said. 'Si hivyo?'

Tr: It is important that when you go somewhere and listen you get, infer what the speakers are trying to say. Read for us chapter three of the book, the first paragraph.

Lr:

Tr: (interrupts) Are you listening?

Lrs: Yes

Lr:

Tr: So inference. What do you now have to say from that? In your own way can you define for me the meaning of the word inference? What is the meaning of what we have read? Who can try? Who can try without looking at the dictionary? Hello. You can try?

Lr 1: I think er...

Tr: Somebody else?

Lr 2: Something that you can find indirectly from what you have read without being told.

Tr: Yeah. Something that you can find out, like Waiyaki can have thoughts like these, what does it mean? Laughing at jokes like when you want to listen to somebody like on a parents day or an AGM or on a prayer day. If I want to know that somebody is listening to me I am sure I can. If I said or if they came here and if they said all of us will stay here until January. What shall we do?

Lrs: Eh! Ee!

Tr: It is a joke eh? Because we know there is time for everything. Then we are laughing at jokes. Who has a joke here even in your mother tongue? In vernacular. Literature continues throughout Africa so 'zungumza hiyo lugha yako'. Anything that can make us laugh. Yes 'leta hiyo story yako'

Lr: (in Luhya.....) 'shukuru kuicha'..... (laughter from class)

Tr: Then we are eager to listen to that, aren't we eager to listen to that? Somebody else?

Lr: (In Luhya...) 'kuicha kumuliro'...

Tr: We know we are laughing because we are listening. Lastly, we have the last item today; critically evaluating the message and comparing it with our existing knowledge or experiences. Read that item number five, number six.....

Lr: Critically evaluating the message and comparing it with your existing knowledge or experience.

Tr: So when you are listening it is very important that you get the message. There should be something that you know. Like there is that question. What is the question? (reads) Just read for us page 125. Just read for us that part. I want to pick someone who does not want to talk. Yes read. Attention please.

Lr: (Blub river between) Interruption midway

Tr: May I just ask a question? When you are reading we want to get you. Look at the words you are reading please. Somebody else continue.

Lr 2: (Blurb R/B)

Tr: I want to believe that in listening and speaking, we must be able to attain and get whatever we dream of. If I stood here and told you deliver individual speeches, what item will you talk about? Because you must begin from what you know to what you don't know. Like when somebody says in listening and speaking..... I have always told you that er can someone pronounce these words. Yeah?

Lr: /iju/

Tr: I cannot be able to pronounce emancipation. I wrote these two words for a purpose. That in speaking there is what we call innuendo. That sometimes we can be able to derive the meaning from........ But then we have these words in this book, where are they? Read them. You have them? Page?

Lr: One eighty seven 
Tr: So can somebody read that first paragraph please. I want somebody to read for us that paragraph that has those words.

Lr: I have a dream. Every hill of Abraham

Tr: Somebody said that the way you pronounce a word is the way you were brought up. Do you support that theory?

Lr: $\mathrm{Me}$

Tr: All of us?

Lr: Yes

Tr: So you are listening? I want to believe that in this world there is no way you can pronounce words like shop and soap.

Lrs: The Obamas!

Tr: The Obamas? And 'papa na'

Lrs: 'Papa na baba!' The Luhyias

Tr: So let us pronounce these words, 'interposition' and 'emancipation'. It is a very long, long word. How long are you going to spend pronouncing? Pronounce it.

Lr 1: Emancipation

Tr: Yes another one?

Lr: Interposition

Tr: You see. So if you don't know how to pronounce, don't hide. Just say it. Don't hide your vocals. Just pronounce so you can be listened to, is not so?

Lrs: Yes

Tr: Somebody else?

Lr: Interposition

Tr: I want somebody to imagine that you have been sent somewhere and you didn't go. You took a long time. You were sent to the granary and you had not done that. You didn't go. Your father is very angry. Now he has threatened to kill you. What are you going to tell him? What are you going to say? We are listening now! Speak to dad. (repeats) He....... (pause) Hello you.

Lr: I became sick and decided to go to hospital.

Tr: I became sick and decided to go to hospital. Will your father get it from you that you are sincere in what you are saying? Say it again.

Lr: I became ........ I went there but there was nobody.

Tr: So when you are speaking to somebody you must know who he is. Like you are talking to the principal for example. You want a bus to go for a trip.

Lrs: Eeeh!

Tr: How are you going to tell her that please, and you want her to listen to you. How will you convince her? No, not you, I want someone...... When I talk about the principal. We are not talking about the principal of Lokhokho. No, no, no,, not you, I think you have a 'homa'. Will you start in a low tone or a high tone?

Lrs: Low.

Tr: Come, come. Stand. Ok. This is the principal. Let us listen please.

Lr: Excuse me madam.

'PRINCIPAL': Yes

Lr: I would like to ask for a bus to take our Drama club to Kamusinga.

Tr: I think we are learning something. I want to pick somebody to do it. Come. Please be fast. Come, come, concentrate. Let us listen please.

Lr: Excuse me madam.

'PRINCIPAL': Yes

Lr: As the music group we would like you to offer us with the bus to take us to Friends School Kamusinga.

Tr: And then we go to these. Finally who can define the word intonation? And then these (writes intonation, pitch, tempo and enunciation on the B/B) What is the meaning of these words? Read from the dictionary. What is intonation?

Lr: The rise and fall of the voice.

Tr: So pitch. What is pitch?

Lr: How high or low a sound is, especially a musical note.

Tr: What is enunciation? (repeats)

Lr 2: To say or pronounce words clearly.

Tr: The clarity. What is tempo?

Lr: The speed or rhythm of a piece of music. 
Tr: This is what matters a lot when you clearly pronounce words. You can go somewhere and pronounce words wrongly then you are not given what you want. You can go there and say these are the problems of pronunciation for example shop and soap. I want to read and lead. There are readers and not leaders. Who said that? Let us not confuse these words. But the problem with these languages is that we are given these words form one language. Like I have always had a problem with the word 'issue'. Is it /iswu/ or /iju/? There is no ' $h$ ' here, although its silent. So when you are pronouncing it avoid reading it as though there is a ' $h$ ' We end our lesson here. Have a good day. May be our visitor has something to say.

Rsr: Thank you very much. This has been a good class. I would like to echo what your teacher told you. That let us not fear to speak. Just say what you wish to say and when you make a mistake, you will be corrected.

Tr: Thank you.

In these classrooms, the learners answered questions, read aloud, pronounced, narrated, asked questions, role-played, discussed and led discussions. However, as earlier noted very little time was spent by students carrying out these roles. Of the total 442 minutes ( 7.36 hours) lessons, the learner used 121 minutes while the teacher used around 321 minutes. The learner used $27 \%$ of the time. This means that the students were not provided adequate opportunity to communicate by communicating. What is more, the learning activities were not selected according to the interests of the learner. The activities observed in the classrooms were those that were already pre-arranged in the class textbooks. These books were written for various learners. Specific learner interests were therefore not taken into account. None of the teachers restructured the activities to suit his unique learners in their unique environment.

In lesson 9, where the topic was pronunciation, the lesson lasted thirty four minutes. Of the thirty-four minutes, six learners read out words from the passage as directed by the teacher. This exercise lasted hardly one minute. Later the teacher asked some questions and nine learners responded. Answering questions lasted two minutes. The answers were given in monosyllables. This therefore showed that the learners had spent just three minutes of the lesson time while the teacher spent thirty one minutes. This means that that class was teacherdominated. Table 1 highlights this information.

Table 1: Time Spent by Learners on Listening and Speaking

\begin{tabular}{lcl}
\hline Lesson & $\begin{array}{c}\text { Duration } \\
\text { lesson in minutes }\end{array}$ & of \\
\hline 1 & 23 & 7 \\
2 & 53 & 3 \\
3 & 27 & 3 \\
4 & 34 & 3 \\
5 & 29 & 6 \\
6 & 38 & 6 \\
7 & 26 & 4 \\
8 & 23 & 19 \\
9 & 32 & 15 \\
10 & 30 & 7 \\
11 & 40 & 22 \\
12 & 27 & 7 \\
13 & 40 & 17 \\
14 & 20 & 2 \\
Total & $\mathbf{4 4 2}$ & $\mathbf{1 2 1}$ \\
\hline
\end{tabular}

Indeed most of the lessons except lesson 13 took this trend. Even when it was a fact that this was a listening and speaking lesson the tendency was for the teachers to dominate the classroom talk. The teacher did not sit back and listen for long. He explained, demonstrated, questioned and even read texts. In lessons 3 and 6 the teacher read out the poem aloud and where they allowed the learners to read, it was as a group. For example lesson 6:

\section{Lesson 6: Sample Observed Lesson (Teacher Reads aloud with the Students)}

Tr: I would like us to go over the oral poem and er I would like you to read through to understand and then we shall look at the questions but only er I want us to go through the poem first I think we can read the poem without putting so much concentration so much on answering the questions. Then we shall look at the questions to try and answer them. Let me read you the questions. The first question, what happens when the persona sees the beauty on his beloved's face? That is one question you should be prepared to get answers for from the oral poem. Secondly, whom does the persona refer to as the daughter of my mother-in-law? Find out who it is. Thirdly, what does the persona compare his beloved's face with? Number four what resolution does the persona make at the end of the poem? Fifthly, what is the economic activity of the people from which the poem is 
taken? You are supposed to answer that. Then question number six, give two adjectives used in the song and use them in sentences of your own. So we shall be expected to construct sentences using two adjectives that are found in the oral poem. Then lastly, find out stylistic devices used in the poem and I believe this poem has a number. On the issues of literary language, remember the difference between literal and literary language as poets usually use language that is unique. So you will appreciate the uniqueness of language and we shall find that from the poem. Oh then we shall look at poetic license. What is poetic license? At the end of it, we shall have another poem on page 132. On page 132, you will find another one er I will prefer to read aloud, so that we get statements that will give tone. Remember when we were in form two we learnt about attitude, we have also heard about tone so we shall be expected to find the tone that will have been used in the second poem, 'I Love You My Gentle One' on page 132. How do we read this poem? Do we go through it as a class or do I allow you to go through it silently?

Lrs: Loudly as a class. We go through orally.......... as a class.

Tr: Order! Ei! I think you guys are excited. We are going to read it aloud as a class.

Lr: Yes!

Tr: You can take your positions so that we can read. We are going to read it. We are going to read it aloud as a class after which we shall answer the questions. Before I make my comments on the same are you all ready? Are you there?

Lrs: Yes

Tr: Ready?

Lrs: Yes

Tr: Now. Three, two, one, go!

Some teachers did assist their learners by providing them with frameworks, patterns and rules. In the field, this was observed in lessons 1,2,12 and 14. Here, though minimally, the teachers made an attempt of providing context for language use, they demonstrated, and explained how some activities were to be carried out.

\section{Sample Lesson 1: Provision of Context for Language use}

Tr: Another sign

Lrs: (Somebody comes up and nods)

Tr: When you shake your head upwards. Upward movement of your head or you move it. You do this (demonstrates- nods). Its means?

Lrs: Nod?

Tr: It means? Yes you?

Lrs: Nodding

Tr: It means you have accepted something. Any other sign that will communicate something?

Lr: (Signals - puts finger in mouth).

Tr: Yes you put your finger in your mouth. What does this mean?

Lr: Silence

Tr: You keep quiet or remain?

Lrs: Silent

Tr: I want us to put ourselves into five groups of five five then we will do...

On motivation, there was an attempt to motivate the learners while making them feel secure and valuable. Such teachers did not harshly admonish those who made mistakes. Instead the teachers corrected them kindly and reinforced those who gave the correct answers for example lessons 5, 14 \& 12 . Generally the atmosphere was warm and relaxed for example in lesson 14. The activities provided were interesting. The learners seemed to enjoy the group work. In fact in lesson nine for example, the teacher had to cut short the discussions as it appeared the learners wished to continue discussing.

However, some teachers did not motivate the learners. They harshly corrected or snapped at those who made mistakes for example lesson two. Others made fun of some learner's weaknesses. In lesson 7 this went on as shown below.

\section{Sample Observed Lesson 7}

Tr: Therefore, the word here is pork. Shibweche?

Lr: I think the word here is /pok/. (Inaudible. At the end others laugh) I think the word is /bok/

Tr: He always does that. After saying something right he then messes it again. (Laughter from class)

Gentlemen, home and pork, these are the same. They have the same sound. Alright?

Lrs: Yes 
This was against the notion that learners should be made to know that mistakes are normal and they are part of the language learning process. Going against this spirit as this teacher did would simply discourage the learner.

In Summary, the role of the teacher as a patient listener who talks less and listens more was only clearly seen in lesson thirteen. There, the teacher acted as the facilitator who set up the exercise and stepped back to observe, occasionally correcting, prompting, settling disagreements, clarifying and ensuring the discussion went on. She acted as a referee.

\section{Sample CLT Lesson, Lesson 13, Form 3 Literature, 40 Minutes, 35 Learners}

Tr: Good morning class.

Lr: Good morning Madam.

Tr: Let us go straight to our discussion. Which group is presenting? I hope they are ready. Please come forward. (learner comes forward)

Lr: Our group is going to present to you the theme of jealousy. Jealousy is the feeling of anger we are having because someone is better than us. So we may say we are able to come out with the character whereby we see jealousy will come about. First we see Kabonyi and Waiyaki. We find that Kabonyi he felt very jealous when the name Waiyaki is being mentioned out. This is when Waiyaki calls out a meeting for the preparation of the school. Many of the people in the ridge called out Waiyaki. Then we see jealousy coming about between Kabonyi and Waiyaki. Here is when after the break of education we see Waiyaki has been given power by his father to rule over the Kiama. So Kabonyi also knows the secrets of the tribe. This is because we see that Kabonyi was older than Waiyaki so he felt jealousy that he was the one who was given power to rule the tribe. Then we see jealousy between Kamau and Waiyaki whereby whenever Kamau would see Waiyaki standing next to Nyambura he would go tell the matter to his father Kabonyi. Then another jealousy comes from Waiyaki, Kabonyi and Kamau. Here we find that when Waiyaki happened to establish many schools we see Kabonyi and his son felt jealousy because they wanted to be the ones so they felt jealousy. Another jealousy comes between Kamau and Waiyaki, where we find that Kamau felt jealousy to Waiyaki because when he could see Waiyaki coming from Joshua's home he could report to the elders. A good example is when Waiyaki was seen coming from Joshua's church. This is found on page 181. So here we see Kamau went to report the matter to his father, Kabonyi. Then another jealousy can be seen between the two ridges Kameno and Makuyu. We see that here Makuyu felt jealousy to Kameno because Makuyu was a place of religion while Kameno was a place for trade. So Kameno refused to bring about Christianity in their region. Another thing, another jealousy was seen whereby Makuyu felt jealousy to Kameno because Kameno they normally produced more heroes than Makuyu. Among heroes of the Kameno we find Kamiri, Waciori and Mugo wa Kibiro who prophesied about the coming of the white man. Jealousy between Kabonyi and Waiyaki.Here we find that Kabonyi was aware that Waiyaki was very likely to be the prophesized leader of the area so he decided to hate Waiyaki so that Kabonyi can become the leader of the Kiama. Then the jealousy comes where Kamau abused him that his father was a Whiteman's convert then Kamau abused Kinuthia that his father died poor. Another jealousy was between Waiyaki and Joshua. We see that Waiyaki feels jealousy because he felt unfaithful and he promised his father long ago to be true to the tribe and church. So we find this in chapter seventeen. So this was the presentation of the group about the theme of jealousy. So whoever has a question or any addition or comma on the presentation is welcome.

Lr 2: There is a place where you said that Waiyaki was given power to rule over the Kiama but me I feel that it was Kabonyi who was the leader of the Kiama. So how can you say it was Waiyaki who was the leader?

Lr 1: Let me tell you, Chege was one of the leaders in the area, isn't it? So Chege was the one who was ruling that Kiama. So when he was about to die he called his son and told him that since he was going to die, he was going to give him power so that he can be able to run affairs of the Kiama. Yes?

Lr: You show us where it is written that Chege is the leader of the Kiama because it was Kabonyi.

Tr: The group help him.

Lr 1: Group two please can you respond. (Mild laughter) our group

Tr: Any other member of the class?

Lr 1: Any other member?

Lr: I have a point to add there that he was one of the leaders of the Kiama. I want to say that Waiyaki was given power by his father because since his childhood the father knew he was going to be a 
leader so the election of Waiyaki to the Kiama was because of the ancient prophecy. But the election in the Kiama was because the elders saw him as an able leader.

Lr: Do you agree that Kabonyi was the one given power by his father? (laughter)

Lrs: Waiyaki. Waiyaki

Tr: What does the class feel about that?

Lr: I wanted to give a suggestion.

Tr: A suggestion?

Lr: Yes a suggestion that Waiyaki was not given power by his father.

Tr: Daniel?

Lr: I agree he was given power by his father but the Kiama is the one which elected him because he was the one who was educated.

Tr: So how does the class look at it? Chege taking Waiyaki to the sacred grove by telling him about the ancient prophecy, what was he doing? And what does this mean? He was actually empowering him and remember in the text it is said it was only Waiyaki and perhaps Kabonyi who knew the prophecy, the ancient prophecy. So he felt that he was actually passing the information to the son. Taking all the way to the sacred grove, I tend to feel that it was the only way of empowering although a member has said that the Kiama will soon ask Waiyaki to take Chege's place that the Kiama was formed now that there was that resistance to the ideas of the Whiteman. And this Kiama was where Waiyaki was made as one of the members and even given a post there, something that Kabonyi didn't really like. So that is how the jealousy comes in. Yes any other comment?

Lr: I heard you say that among the themes of jealousy is between Waiyaki and Kamau. So Kamau was jealous for Waiyaki. A good example is seen when Waiyaki is seen when he was seen standing with Nyambura at the river. You see it is only Kamau who saw him. So on that matter he went and told his father that he had seen Waiyaki standing with Joshua's daughter and yet Joshua's daughter was a 'Christianity'. Now was that jealousy?

Tr: Now in this case the two have interest in Nyambura and one is winning the hand of Nyambura so definitely this must have brought in some animosity bad feelings. Why should Waiyaki be the one to be seen with Nyambura and not me? And not er ... er .... who?

Lr: Kamau

Tr: Kamau. So may be at that point, let us have additional points. May be this group did not exhaust all points.

Lr: There is jealousy between Joshua and Waiyaki because Waiyaki has many people following him and yet the Christians were not all that many. So Joshua feels jealousy from Waiyaki. So he feels jealousy for the progress

Tr: There is jealousy between Joshua and Kabonyi?

Lrs: Waiyaki.

Tr: Waiyaki. That is correct .It is between Joshua and waiyaki because for Joshua he sees the way the traditionalists are really coming up. The fact that they have even burnt a house. The converts' houses. So he looked at it as if the traditionalists led by him so he goes to seek the assistance of the Whiteman so that he can start school to stop the children of the converts from joining the traditional school, sorry the independent schools. Any other point?

Lr: First I think that the theme jealousy was played out clearly at the er- at the school when parents had come when Waiyaki was outlining plans for the school. When it comes to the building of the toilet for the children, some came to see the famous Marioshoni school and when Waiyaki was outlining that you see we see Kabonyi did not like it, because people were admiring Waiyaki. They liked the way he freely mingled and the way he talked. He had a word for every one and a smile for all. He pleased many but not all. At that point jealousy and envy were bound to work. He saw Waiyaki. Kabonyi saw Waiyaki as an outcast, a good for nothing, a boy who came up with rather silly ideas. We see here that there is jealousy. We also see that when the children were entertaining their parents with songs that had Waiyaki's name. We see that er ... the, when the children were saying, the songs were good and we see Kabonyi was ashamed to denounce Waiyaki or rather to ashame him before the crowd. A thing that brings in jelousy. That is all I have.

Tr: That is also an additional point. We see it had evidence given form the text. We should enable our listeners to locate where the author's point of view is. We see jealousy coming up in Kabonyi who is not happy about the excitement that is given to Waiyaki. Any other?

Lr: Jealousy is also shown to Waiyaki when he fails to talk to Nyambura. (laughter)

Tr: Is that jealousy? (laughter)

Lr: Yes Waiyaki felt annoyed when at first she did not want to talk to him. 
Tr: As in?

Lr: I think there is jealousy between Waiyaki and Kamau.

Tr: What does the class think? (pause) There is competition between the two, Kamau and Waiyaki.

Lrs: Waiyaki.

Tr: Er... any other comment?

Lr: (Inaudible mumbles)

Tr: Be audible. He doesn't know whether he is right. Amplify it.

Lr: I think there is jealousy between Kamau and Joshua. This is seen when Waiyaki prays. We also see Joshua when he prays he says oh God 'why didn't you descend on these wicked people' (laughter)

Tr: So you are saying that while that er what goes on in Joshua's mind he is not happy at all about the activities of the traditionalists. So he needed to pray that God may send a curse to the traditionalists. Oh yes. Some feeling of jealousy. Why should they thrive? Why should they continue? According to Joshua who is an ardent follower of Christianity why should they continue being in such darkness? Any other? Are there any additional points?

Lr: In addition, I think there is jealousy forming around Waiyaki and Nyambura since we find that when Nyambura asks Waiyaki where he was going he says that he is going to Kabonyi and this answer to Nyambura shows that they had plans which they were going to discuss. May be to improve the Kiama.

Tr: Which page?

Lr: Page ninety four.

Tr: Page ninety four (pause). So let us pick out these areas and many others. Now we want to asses this group. How has been their work? Anyone can comment.

Lr: I think the group had done 'a good work.' They researched very well. (laughter)

Tr: Very well? Or is it just well? He says the work was well researched. I don't know. What does the class think about that one? Is it well researched work? How about the presenter? Yes?

Lr: I think the group did 'a good work'.

Tr: Did good work. Use articles correctly. Yes?

Lr: I think it is only Patrick who did this work and one of the members.

Tr: How do you know?

Lr: Because others are not responding to questions they are only leaving for the representative to answer.

Tr: So this group can you defend yourself. Those who were in Wanyela's group.

Lr: We all worked together.

Tr: Are you sure? (laughter)

Lr: Yes we only chose one to speak.

Tr: Then you should have participated. Those who did not do participate I think they needed to do something more. They should have done the work for the entire group and given the message to the representative to give to the rest of the class. Get involved. Any other thing?

Lr 1: Any other comment?

Tr: You have something to say?

Lr: To me I think that this group they were in their group, they sat and gave ideas. Now the presenter has all the points only that the other members are not participating.

Tr: They are not participating?

Lr: Yes.

Tr: May be you have not asked them questions. Have you?

Lr: We asked.

Tr: You asked? May be you asked and they were not able to respond to the questions. So I think er ... with that then this group apart from er ... grammatical errors, the use of, and this one goes to all of us, the use of articles and word usage. I don't know why you are in the habit of adding an article to the wrong words. Then somebody says er er we 'feel jealousy to.' Use of also prepositions. Then the tense, as we talk we need to do it in the present. Kabonyi is old not was old. So we use that, then er then er you were talking of another jealousy. Let us use other words such as instance of jealousy is ...... and then from that heroes of Kameno. This group and many others that are going to present. So with that I must say that the group was exhaustive, although we still expect more information. I said this business of copying for us pages should not be there. You quote and explain the facts. Although you tried but in some instances you did not. So I think with that we stop there. We can give them a hand clap but remember to work as a team so don't work as individuals. Give them one hand clap. (clap). Ok sit down. So let us have the group presenting on 
er er. Let me see. I know people are breathing so hard. (laughter) Religious conflict. Quickly. Religious conflicts and other conflicts. Let us have the group members. Is that work for the group?

Lr A: Yes madam. (pause for around one minute) Here we se that we have traditionalists and Christians so the theme is about these groups. Then (laughter from the class) conflict means that people have different ideas or opinions on issues. In the novel we find there is a conflict. First

Lr B: One, people were determined to hold onto their old traditions of life e.g. Kabonyi didn't want any person to diverge from the tradition.

Tr: Continue.

Lr B: Second, the traditionalists believed that Christianity will never get to any good. The traditionalists believe that Christianity will never come to any good. This is seen where Chege is saying that Joshua will not have sold his heart to the Whiteman. On page 27 Kabonyi makes this statement. Next, the traditionalists contaminate and believe that Kabonyi believes that Christians are contaminating traditions. Clearly showing that evil will come out of any association with the new religion. There is also conflict the time when we saw the children of the traditionalists being sent out of Siriana mission centre, which was a result of Muthoni's death, after the circumcision. The Christians believe that tradition was all evil and so there was no way they could go the same way with the traditionalists. These were words from Joshua to Kabonyi. Traditionalists believe that Christians they would bring division to the tribe. They would spoil all that was good and beautiful to the tribe, like circumcision. So we.......... so before (laughter at hesitation)

Lr A: Let me clear about the idea of circumcision. The traditionalist believed that this will bring down what has been preached against. This can be found on page 125. This was when the Kiama summoned Waiyaki at night.

Lr B: Then another conflict between Waiyaki and the Kiama, where they are disagreeing over whether to marry Nyambura. They accuse him of going to Joshua's church. This was when he was summoned by the Kiama at night. Then they accusing him. Then when Kabonyi is in conflict with Waiyaki. He considers him young. When he said he cannot lead the rest. Kabonyi says Waiyaki is only a boy. Then as Waiyaki considers education the other elders are against the White men. They only went on assuming that Waiyaki would lead them to the right way. Another conflict is between Waiyaki and Joshua. This is when Joshua chases Waiyaki at night when Waiyaki went to inform him about the Kiama's plan. Joshua turned against Waiyaki chasing him away and telling him that he was a sinner. Then lastly conflict between Kinuthia and Kamau, when they were looking after the cattle. They fought because they had abused each. There is also conflict between the ridges where we found that Makuyu had taken the way of the White man, the Kameno stick to traditions and they are considering some as an ambition to the land.

Lr B: So class, I will er request that we give one comment about the presentation, because our time is up (pause). Yes the presenter, the presentation. Comments. Quickly. Yes Beatrice.

Lr: I think that the presentation was actually very good.

Tr: Very good (laughter from class)

Lr: The presentation was good but the research shallow.

Tr: Shallow. That is a negative point. Class take note of that.

Lr: One speaker was speaking more that the other.

Tr: There should be one speaker. As much as you put in variation, he says one speaker was speaking more that the other. But then that was the arrangement of the group. Yes Ahono.

Lr: The presentation was not well researched by all.

Tr: Aha. They are still insisting that the presentation was not well researched especially from this presenter here. This one, take note of that. Yes?

Lr: Mine is that the presentation was er did not bring out the conflict

clearly

Tr: Really? Really? Class do you agree?

Lrs: No.

Tr: Do you? In your opinion? Ok in his opinion they did not bring out conflict clearly. We shall consult them at a later stage. So class I am sure because of time we cannot give the additional points, we cannot give the additional points but when I come next that is where we shall start from. Otherwise er just the same problem goes round. We have a problem with the word 'can' and 'then'. Then if you are sequencing your work start with firstly, secondly, thirdly and then fourthly. You don't say first, third, four and I have said we use of tense. Use of tense. We see children not we saw children not we saw. We were not there. This is just something you have been given to read. Then something to do with the articles. We talk of after circumcision. Use of articles. We 
shall point out others when we shall be tearing this group into pieces, the next lesson. Otherwise thank you very much for being patient. Madam can you give a comment?

Rsr: Thank you very much. It has been a very good class. I have enjoyed.

I think I am happy with the presenters. I have learnt one thing. My students present, others comment, I think I am very happy with the comments that have come from the rest. (Claps from class). Thank you very much. It is actually one of the best methods of learning literature. When it comes from you, you are internalizing it instead of it coming from the teacher. I just want to encourage you to go on with the same spirit. Thank you very much. (Class claps)

Tr: What do we tell her as she goes?

Lrs: Greet them

Rsr: I will greet them. Pause. Thank you madam. Thank you madam.

In lessons 1, 2, 8 and 9, the teacher acted as facilitator but only for a short while. In lesson 1, the teacher talked for 16 minutes while the learners spent 7 minutes. In lesson two, the teacher-talk lasted 50 minutes while learner-talk took 3 minutes in lesson 8 the teacher spent 4 minutes while the learners spent 19 minutes. Lesson 9 had teacher talk lasting 17 minutes while learner talk lasted 15 minutes. In total only 5 lessons had teachers allow learners some time to listen and talk. These were lessons 13, 1, 8, 2 and 9.

From the foregoing presentation, it is evident that majority of the teachers in Lugari did not step back and let their students carry out communicative tasks. The classrooms were not noisy either. The teachers did not act as referees to the classroom activities. They chose to take centre stage in the learning process, choosing to be the sole proprietors of knowledge.

The study aimed at finding out whether the communication activities that focus on sociolinguistic, strategic and grammatical competences are used to teach listening and speaking. These three skills help learners build their confidence level, improve creative thinking and augment linguistic creativity. Communication should enable learners to negotiate meanings effectively and efficiently. It was found that there were very few communicative activities assigned to students. Those used included reading aloud, questioning, narrating, role play, dictation, demonstration, simulation, minimal pair drills, group discussions and oral presentation. However, these activities were very few and the time spent by each very short. Therefore the benefits of such activities could not be reaped to the fullest. This can be seen in Table 2 .

Table 2: Learner Roles in the Classroom

\begin{tabular}{ll}
\multicolumn{1}{c}{ Table 2: Learner Roles in the Classroom } \\
\hline CLT Component & No. of participants \\
\hline Minimal pair drills & 3 \\
Dictation & 195 \\
Oral presentation & 9 \\
Narration & 2 \\
Simulation & 2 \\
Demonstration & 4 \\
Role-play & 11 \\
Group discussion & 74 \\
Reading aloud & 111 \\
Listening comprehension & - \\
Questioning & 5 \\
Answering questions &
\end{tabular}

\section{Discussion}

Teachers and learners were observed during listening and speaking lessons. The motive of the observation schedule was to find out what roles the teacher and learner played respectively in a listening and speaking lesson. Those observations would further go to confirm if the teachers were using the CLT approach or not. An observation checklist which outlined the recommended learner and teacher roles respectively was drawn. In the checklist, about twenty roles for teachers and seventeen for learners in a CLT listening and speaking class were listed. Such findings go to support what a onetime chief inspector of schools [16] said. According to them, the development of competence depends to a large extent on whether the students are given sufficient opportunity to become productively involved in practical language- using situations. Many schools in Kenya fail to provide such opportunities.

\subsection{Teacher Roles}

They include teachers demonstrating, directing, explaining, prompting, resolving disagreement, monitoring work silently, supervising, controlling, providing language items, creating context for language use, grouping learners, evaluating, participating as co-communicator, advising, introducing, giving speaking tasks, questioning, dictating, listening and correcting. 
The roles the teacher plays in a broad sense cut him out as a 'facilitator of learning' who may need to form in a variety of specific roles, separately or simultaneously [1]. However, teachers in Lugari District concentrated on the traditional role of instructor. In only one lesson out of the fourteen observed did the teacher facilitate the lesson. This was in lesson 13. In the rest, the teacher spent a lot of time instructing the learner. In any case, they did not give learner tasks that required facilitative roles on the part of the teacher. There were very minimal learner-centred activities that called for the teacher to act as manager. There were two cases where there was an attempt to use the discussion method. The discussion, however, lasted for a very short time. Nonetheless, the two teachers came out as monitors and supervisors of the discussion.

Though the two teachers used the discussion method briefly, a big discrepancy was noted. This was meant to be an English lesson but the discussions were held in Kiswahili and Sheng'. The teacher appeared to encourage the use of the two languages at the expense of English. These findings therefore show that the teachers are not reflective. Reflective teachers need to investigate how much time is spent on talking and listening in a whole class teaching session. The teacher needs to ask questions like: how much talking is there? Who is doing the talking? Are there differences between boys and girls? High and low achievers? What is the teacher talk about? What is the pupil talk about? If these teachers did this, they would have changed their mode of teaching.

On the whole it could be said that the teachers in this study did not play the roles advocated for by the CLT approach. They preferred to use the traditional teacher-centred, lecture method, punctuating with questions which were answered by the teacher himself or required answers available in the text which the learner could easily draw.

\subsection{Learner Roles}

These included role playing, debating, discussing, leading discussions, asking questions, responding, describing, sharing, narrating, performing riddles, pronouncing, reading aloud, reporting, paraphrasing, reviewing, answering questions, listening and paying attention to non-verbal cues. Widdowson [2] suggests that language teachers needed to assist learners by providing them with frameworks, patterns and rules to develop their communicative language skills. In the field, this was observed in lessons 1, 2, 12 and 14. Here, though minimally, the teachers made an attempt of providing context for language use; they demonstrated; and explained how some activities were to be carried out.

As noted earlier, teachers asked questions which had answers from textbooks. In addition, others asked leading questions. It was no wonder that the biggest role the learners played was answering questions. They answered questions in chorus, in monosyllables or direct statements from text. These ways of answering questions do not help to enhance communicative competence.

\section{Conclusion And Recommendations}

A significant finding from the study was that while learners were passive participants in the process of learning the listening and speaking skills, the teacher played a very active role. He took centre stage. The teacher concentrated on instructing the learner. He planned the lesson alone, and while in class he talked, asked questions, demonstrated, gave notes, answered questions, explained, narrated, described, responded and even read extracts. The learner was hardly involved. For communicative competence to be achieved, there needs to be less teacher control and more pupil centeredness in any listening and speaking task.

\section{References}

[1] Littlewood, W. (1981). Communicative Language Teaching. Cambridge: Cambridge University Press.

[2] Widdowson, G. H. (2001). Aspects of Language Teaching. Oxford: Oxford University Press.

[3] Hendrickson, J. M. (1991). On Communicative Language Teaching. Hispania, 74(1), 197-198.

[4] Gerngross and Pucha (1993). Communicative Language Teaching: An Introduction and Sample Activities. In A. Galloway, Communicative Language Teaching: An Introduction and Sample Activities. Eric Educational Reports. Retrieved July 21, 2010 from Web FindArticles.com

[5] A. Galloway, Communicative Language Teaching: An Introduction and Sample Activities. Eric Educational Reports. Retrieved July 21, 2010 from Web FindArticles.com

[6] Larsen-Freeman, D. (1986). Techniques and Principles in Language Teaching. Oxford: Oxford University Press.

[7] Rono et al. (2006). Memory and Forgetting. In D. M. Ndetei, (Ed.). Clinical Psychiatry and mental health. Nairobi: AMREF.

[8] Nyaga, M. C. (1994). Motivating Factors for Kiembu Kiswahili-English Code-Choice \& Code- Switching: A case Study of Kavutiri Sec. School - Embu (Unpublished M. Phil Thesis). Moi University.

[9] Hymes, D. (1971). On Communicative Competence. Philadelphia: University of Pennsylvania.

[10] Ministry of Education (1992). A Guide to English Teaching in Kenyan Secondary Schools. Nairobi: K.I.E

[11] Theuri, C. G. (1985). A Study of Communication and English Language Use in Standard Four Rural Classrooms in Kangema North Division, Muranga District (Unpublished M.Ed. Dissertation). University of Nairobi.

[12] Juma, L. (1991). The Structure of Classroom Discourse in Kenya Secondary Schools (Unpublished M.A. Dissertation). Kenyatta University.

[13] Makhulo, J. O. (1984). A Study of Verbal Interaction in Upper Primary in some Selected Schools in Hamisi Division of Kakamega (Unpublished M.Ed Dissertation). University of Nairobi. 
[14] Kenya National Examinations Council (KNEC) (2006). KCSE Newsletter. Nairobi: KNEC.

[15] Odeo, I. I. (2003). Oral questioning in the pedagogy of Kiswahili Grammar in Secondary schools in Bungoma District (Unpublished Ph.D Thesis). Moi University.

[16] Barasa, L. P., \& Ong'ondo, C. (2006). Impact of Drama on English language Teaching. The Educator Journal, 1, 181-189. Eldoret: Moi University Press. 